\title{
Emergência de plântulas de Astrocaryum aculeatum G. May. em função da temperatura e do período de embebição das sementes ${ }^{1}$
}

\author{
Patrícia NAZÁRIO², Sidney Alberto do Nascimento FERREIRA³
}

\section{RESUMO}

O presente trabalho teve por objetivo avaliar a emergência de plântulas de Astrocaryum aculeatum a partir de sementes submetidas a diferentes temperaturas e períodos de embebição. O delineamento experimental foi inteiramente casualizado, em esquema fatorial 4 (temperaturas de embebição em água: $25^{\circ} \mathrm{C}, 30^{\circ} \mathrm{C}, 35^{\circ} \mathrm{C}$ e $40^{\circ} \mathrm{C}$ ) X 3 (períodos de embebição: 2 , 4 e 6 dias), com testemunha (sem embebição) e com quatro repetiçóes. As semeaduras foram realizadas em viveiro. A emergência e o índice de velocidade de emergência só diferiram entre a testemunha e os tratamentos aplicados, independentes do período e da temperatura, com resultados favoráveis para a embebição das sementes. O tempo médio de emergência apresentou efeito de interação significativo, destacando-se a utilização da temperatura de embebição de $40^{\circ} \mathrm{C}$, associada ao período de 4 dias, que proporcionou um menor tempo médio (163 dias). $\mathrm{O}$ tempo inicial de emergência foi menor na temperatura de $35^{\circ} \mathrm{C}$ (80 dias), enquanto o tempo final de emergência não apresentou diferença entre as médias. Sementes embebidas por 2 dias apresentaram $50 \%$ de sementes mortas ao final do experimento, enquanto as embebidas por 4 dias, apenas 38\%. A emergência de plântulas de $A$. aculeatum foi favorecida pela embebição, independente da temperatura e do período utilizados.

PALAVRAS-CHAVE: Palmeira, tucumã, germinação, dormência, tempo de emergência.

\section{Emergence of Astrocaryum aculeatum seedlings according temperature and soaking period of seeds}

\begin{abstract}
This study evaluated the seedling emergence of Astrocaryum aculetum seeds soaked in water for different periods at different temperatures. The experimental design was entirely randomized, in factorial 4 (temperatures of soaking in water: $25^{\circ} \mathrm{C}, 30^{\circ} \mathrm{C}$, $35^{\circ} \mathrm{C} \mathrm{e} 40^{\circ} \mathrm{C}$ ) X 3 (period of soaking: 2, 4 and 6 days), additional treatment (control, without soaking), with four replications. Before (control) and after the soaking periods in different temperatures, the seeds were planted in nursery. The emergence and its velocity differed only in the comparison of the control with the applied treatments, with favorable results of all soak treatments, independent of temperature and duration. The mean time of emergence presented a significant interaction effect, with the four day $40^{\circ} \mathrm{C}$ soaking temperature period, presenting a lower mean time (163 days). The initial emergence time was lower in $35^{\circ} \mathrm{C}$ temperature (80 days), while the final time didn't show differences among means. Seeds soaked for two days had $50 \%$ dead seeds, while seeds soaked for four days had just $38 \%$. Seedling emergence was favored by soaking, independent of temperature and duration.
\end{abstract}

KEYWORDS: Palm, tucumã, germination, dormancy, time of emergence.

${ }^{1}$ Apoio financeiro FAPEAM 878/ 2003; CAPES

2 Instituto Nacional de Pesquisas da Amazônia. E-mail: patty@inpa.gov.br

${ }^{3}$ Instituto Nacional de Pesquisas da Amazônia. E-mail: sanf@inpa.gov.br 


\section{INTRODUÇÃO}

As palmeiras (Arecaceae) constituem uma família de grande importância ecológica e econômica por apresentarem múltiplos usos. Dentre estas, destaca-se o tucumã (Astrocaryum aculeatum G. May.), cujo produto principal é a polpa dos frutos, muito consumida na Amazônia Central, seja na forma in natura ou como recheios de sanduíches e tapiocas, bem como na forma de doces e sorvetes. As fibras das folhas também são utilizadas para confecção de redes de dormir; o tronco é utilizado para confecção de instrumentos musicais e as sementes são muito apreciadas para o artesanato local (Miranda et al., 2001).

Apesar de constituir uma importante atividade econômica para a região, a obtençẫo dos frutos é feita geralmente de forma extrativista, havendo poucos plantios de $A$. aculeatum. A principal forma de propagaçáo dessa espécie, como de outras palmeiras, é por sementes. Contudo, existem poucas pesquisas sobre o processo de produção de mudas, desde a germinaçáo das sementes. Miranda et al. (2001) informam que as sementes da espécie apresentam dormência, constituindo-se num problema para produção de mudas. A dormência é um fator interno da semente, de grande importância no estudo da germinação, e muitas espécies da família Arecaceae as exibem em diferentes graus (Odetola, 1987).

Alguns estudos têm demonstrado que sementes de Astrocaryum aculeatum apresentam dormência. $\mathrm{Na}$ avaliação da germinaçáa das sementes de tucumá, foi verificado que a retirada do endocarpo favorece a reduçáo do tempo de germinação, de dois anos para 141 dias (Gentil e Ferreira, 2005; Ferreira e Gentil, 2006). Foram observados comportamentos diferenciados quanto à embebição. As sementes não embebidas apresentaram germinação inferior $(58 \%)$ às sementes embebidas por nove dias (70\%), além do tempo médio ser maior (17 dias a mais), caracterizando-se como um processo germinativo mais lento. Apesar dessas vantagens, o período e o tempo médio de germinação são elevados, o que estimula a busca de procedimentos a fim de otimizar os resultados de germinaçáo de sementes de A. aculeatum. Assim sendo, o presente trabalho teve por objetivo avaliar germinaçáo de sementes de Astrocaryum aculeatum submetidas a diferentes temperaturas e períodos de embebição.

\section{MATERIAL E MÉTODOS}

O estudo foi desenvolvido no Laboratório de Sementes e no Viveiro de Germinação da Coordenação de Pesquisas em Ciências Agronômicas (CPCA) do Instituto Nacional de Pesquisas da Amazônia (INPA), em Manaus (AM). Neste estudo, foram utilizadas sementes obtidas a partir de pirenos (semente com endocarpo) provenientes de uma mistura de progênies adquiridos junto à Feira do Parque Dez, em Manaus.
Os pirenos foram imersos em água por três dias com troca diária, a fim de facilitar a retirada de resíduos remanescentes da polpa (mesocarpo). A remoção consistiu da fricçáo dos pirenos com água e areia. Em seguida, estes foram postos para secar em ambiente com umidade relativa do ar média de $84 \%$ e temperatura média mínima de $25,2^{\circ} \mathrm{C}$ e média máxima de $27,8^{\circ} \mathrm{C}$, por um período de 30 dias, quando a maioria das sementes havia se soltado do endocarpo. A perda de água foi monitorada a cada dois dias durante a secagem, sendo pesadas 20 repetiçóes de 50 pirenos, em balança de precisão. No início da secagem foi determinado o grau de umidade dos pirenos, método estufa a $105 \pm 3^{\circ} \mathrm{C}$ (Brasil, 1992), utilizando 4 repetiçóes de 5 unidades. Com base no grau de umidade inicial e nas perdas de massa (ou água) foi estimado o teor de água dos pirenos durante o período de secagem.

Após a secagem dos pirenos, foram extraídas as sementes a partir da quebra do endocarpo, conforme Ferreira e Gentil (2006). As sementes obtidas passaram por uma triagem, onde foram eliminadas aquelas que tinham sofrido algum dano físico no tegumento.

As sementes foram colocadas para embeber em água, sob as temperaturas de $25 \pm 1^{\circ} \mathrm{C}$ (ambiente), $30 \pm 1^{\circ} \mathrm{C}, 35 \pm 1^{\circ} \mathrm{C}$ e $40 \pm 1^{\circ} \mathrm{C}$, com troca diária da água, pelos períodos de 2,4 e 6 dias; as três últimas condiçôes de temperaturas foram improvisadas, usando-se banho-maria. Antes da embebição (testemunha) e após os diferentes períodos, nas quatro temperaturas, foi feita determinação do grau de umidade das sementes e instalado teste de emergência de plântulas. $\mathrm{O}$ teor de água foi aferido em estufa a $105 \pm 3^{\circ} \mathrm{C}$, por 24 horas (Brasil, 1992), utilizando 4 repetiçóes de 5 sementes por tratamento; os resultados foram expressos em porcentagem, com base no peso da amostra úmida. O teste de emergência foi instalado em viveiro, coberto com telha de fibra de vidro (temperatura média mínima de $24^{\circ} \mathrm{C}$ e média máxima de $38^{\circ} \mathrm{C}$ ), com semeadura em caixas plásticas, contendo como substrato uma mistura de areia e serragem de madeira (relaçáo volumétrica de 1:1); o poro germinativo foi posicionado para o lado, formando um ângulo de $45^{\circ} \mathrm{com}$ a superfície do substrato.

A avaliação da emergência iniciou aos 20 dias após a semeadura e foram feitas contagens do número de plântulas a cada 10 dias, até os 360 dias. O critério para a avaliação da emergência foi a emissáo da segunda bainha. Esses dados foram transformados em porcentagem e, a partir dos mesmos, foram calculados o índice de velocidade de emergência (IVE) (Maguire, 1962), o tempo inicial, o tempo final e o tempo médio de emergência (TIE, TFE e TME, respectivamente) (Edwards, 1934). Por meio do Teste de Corte (Brasil, 1992), as sementes remanescentes, não germinadas, foram classificadas em "sementes dormentes" e "sementes mortas". Essa classificação foi feita pela exposição do embriāo, a partir de cortes na semente, sendo consideradas "mortas" as sementes 
que apresentavam deterioração visível e "dormentes" as que apresentavam-se aparentemente viáveis.

O experimento foi instalado em delineamento inteiramente casualizado, em esquema fatorial (4 temperaturas de embebição X 3 períodos de embebição), mais tratamento adicional (testemunha, sem embebição), com quatro repetiçôes de 25 sementes. Após teste de normalidade e homogeneidade, para efeito de análise de variância, os dados expressos em porcentagem foram transformados em arco-seno $\sqrt{ }(\mathrm{x} / 100)$. A comparação entre as médias foi feita por meio do teste de Tukey ao nível de 5\% de probabilidade. Quando conveniente foi realizado estudo de regressão.

\section{RESULTADOS E DISCUSSÃO}

Durante o período de 30 dias de secagem dos pirenos, observou-se que o teor de água caiu gradativamente de 28,9\% para $17,6 \%$ (Figura 1). Embora os pirenos tenham perdido $39,1 \%$ do seu teor de água inicial, essa perda não foi suficiente para "soltar" as sementes do endocarpo, em grande parte dos pirenos, ocasionando uma perda de aproximadamente 30\% no processo de extração da semente. A necessidade de períodos diferenciados para que todas as sementes se desprendam do endocarpo está possivelmente relacionada ao fato de tratar-se de pirenos provenientes de uma mistura de progênies, com variaçóes no tamanho (pireno/semente), na espessura do endocarpo e no teor de água. A dificuldade na extração da semente do pireno também pode estar relacionada à estreita associaçáo da semente com o endocarpo, conforme foi observado por Araújo (2005) em Astrocaryum acaule.

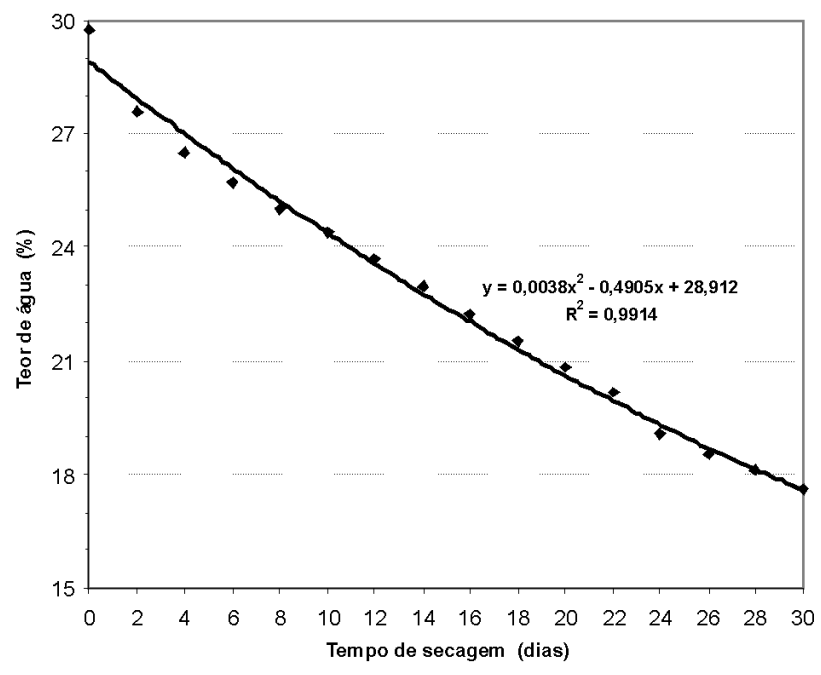

Figura 1 - Teor de água estimado dos pirenos de Astrocaryum aculeatum durante 0 período de 30 dias de secagem.

As variáveis analisadas não apresentaram efeito de interação entre os fatores (temperatura $\mathrm{x}$ período), com exceção do tempo médio de emergência. O grau de umidade das sementes diferiu significativamente apenas entre as sementes embebidas $(30 \%)$ e não embebidas (24\%), independente dos fatores temperatura e período de embebição (Tabela 1). Isso quer dizer que os diferentes níveis de temperatura $\left(25^{\circ} \mathrm{C}, 30^{\circ} \mathrm{C}\right.$, $35^{\circ} \mathrm{C}$ e $40^{\circ} \mathrm{C}$ ) e níveis do período de embebição (2, 4 e 6 dias) não afetaram significativamente o teor de água das sementes. Parte destes resultados, principalmente no que se refere a ausência de diferença entre os níveis dos fatores estudados, pode ser devido ao método de amostragem, ou procedimento, inadequado para a determinação do grau de umidade das sementes de tucumá. Cada semente pesava, aproximadamente, $12 \mathrm{~g}$ e foram utilizadas apenas cinco unidades por repetição. Além do mais, estas não foram fracionadas conforme recomenda as Regras para Análise de Sementes para o caso de sementes grandes (Brasil, 1992), por tratarem-se de sementes oleaginosas, visando evitar perdas de massa pela evaporação de óleos. Outros fatores, não controlados, também podem ter contribuído para estes resultados, como o fato de neste experimento terem sido utilizadas sementes provenientes de mistura de progênies. De qualquer modo, visualiza-se a necessidade de estudos a fim de se determinar o tamanho da amostra e procedimentos adequados para a aferição do teor de água das sementes de tucumá.

A emergência de plântulas de $A$. aculeatum foi superior para as sementes embebidas (32\%, em média) em relação às sementes da testemunha (21\%), que não foram embebidas antes da semeadura (Tabela 1). Por outro lado, a temperatura e o período de embebição não afetaram de modo significativo a emergência, ou seja, a embebiçáo, em qualquer temperatura ou período, favorece a emergência. Este resultado confirma a superioridade da germinação de sementes de tucumã embebidas encontrada por Ferreira e Gentil (2006). No entanto, ressalta-se que em Ferreira e Gentil (2006), tanto para as sementes embebidas quanto para as não embebidas, os valores de germinação foram mais elevados, $70 \%$ e $58 \%$, respectivamente. Vale salientar que no presente trabalho o critério de avaliação utilizado foi a emissão da segunda bainha, enquanto no trabalho de Ferreira e Gentil (2006) foi a formaçãa do botão germinativo, que ocorre, em média, 30 dias antes da emissão da segunda bainha (Gentil e Ferreira, 2005). É também importante lembrar que as sementes utilizadas no presente trabalho eram oriundas de uma mistura de progênies, podendo apresentar alta variabilidade genética. Além disso, não houve controle da idade dos frutos no momento da colheita, que, possivelmente, era diferente entre as progênies. Esse é um fator importante em sementes de palmeiras, a exemplo do que ocorre em Bactris gasipaes, onde a maturidade fisiológica das sementes é atingida cerca de um mês antes da maturação do fruto; a permanência da semente na planta após a maturação aumenta gradativamente a intensidade de dormência (Ferreira, 1996). As sementes de palmeiras são caracterizadas por apresentarem, em alguns casos, grandes 


\begin{tabular}{|c|c|c|c|c|c|c|c|}
\hline Fator & $\begin{array}{c}\text { Teor de água } \\
(\%)\end{array}$ & Emergência (\%) & $\mathrm{TI}$ (dias) ${ }^{1}$ & $\operatorname{TF}(\mathrm{dias})^{1}$ & IVE $^{1}$ & $\begin{array}{l}\text { Sementes } \\
\text { mortas (\%) }\end{array}$ & $\begin{array}{c}\text { Sementes } \\
\text { dormentes }(\%)^{1}\end{array}$ \\
\hline Testemunha & $24^{\star \star}$ & $21^{*}$ & $98 \mathrm{~ns}$ & $262 \mathrm{~ns}$ & $0,033^{*}$ & 44 ns & $31 \mathrm{~ns}$ \\
\hline \multicolumn{8}{|c|}{ Temperatura $\left({ }^{\circ} \mathrm{C}\right)$} \\
\hline 25 & 31 & 29 & $115 b$ & 262 & 0,042 & $41 a b$ & 26 \\
\hline 30 & 30 & 35 & $99 a b$ & 286 & 0,052 & $35 \mathrm{a}$ & 24 \\
\hline 35 & 30 & 34 & $80 a$ & 296 & 0,059 & $48 \mathrm{~b}$ & 15 \\
\hline 40 & 32 & 30 & $92 a b$ & 283 & 0,052 & $47 a b$ & 19 \\
\hline \multicolumn{8}{|l|}{ Período (dias) } \\
\hline 2 & 31 & 29 & 108 & 269 & 0,046 & $50 \mathrm{~b}$ & 17 \\
\hline 4 & 30 & 33 & 95 & 289 & 0,054 & $38 \mathrm{a}$ & 25 \\
\hline 6 & 31 & 33 & 87 & 287 & 0,054 & $40 a b$ & 21 \\
\hline C.V. (\%) & 8 & 17 & 29 & 16 & 32 & 17 & 31 \\
\hline
\end{tabular}

Médias seguidas de letras diferentes, em cada fator, diferem entre si pelo teste de Tukey ao nível de $5 \%$ de probabilidade.

${ }^{\star} \mathrm{e}^{* \star}$ Significam que a testemunha, sem embebição, diferiu em relação aos demais tratamentos, pelo teste $\mathrm{F}$ a $5 \%$ e $1 \%$ de probabilidade, respectivamente.

dificuldades na germinação, devido às características físicas das sementes ou a peculiaridades fisiológicas do processo germinativo (Pinheiro, 1986; Marcus e Banks, 1999). Entre as dificuldades na germinação em sementes de tucumã, pode estar a variação na composição química do endosperma visto que este representa a maior parte da semente e corresponde a 29,7\% do peso do fruto (Moussa e Kahn, 1996). Sendo assim, verifica-se a necessidade da combinação da embebição com outros tratamentos pré-germinativos.

O tempo inicial de emergência diferiu significativamente entre sementes embebidas a $35^{\circ} \mathrm{C}$ (80 dias) e as embebidas à temperatura de $25^{\circ} \mathrm{C}$ (115 dias), a qual não diferiu das demais temperaturas testadas. $\mathrm{O}$ tempo final de emergência não apresentou diferença, tanto em relação à testemunha (sem embebição), quanto aos diferentes níveis dos dois fatores estudados (Tabela 1). Isso sugere que as sementes desta espécie devem passar por um período, variando de 2 a 6 dias, sob condiçôes úmidas e com temperatura acima da ambiente $\left(35^{\circ} \mathrm{C}\right)$, para que ocorra uma antecipação no início da germinaçáo. Sob condiçóes naturais, isso pode ocorrer por meio da dispersão, que é feita principalmente pela cutia (Dasyprocta sp.), que enterra as sementes no solo (Pessoni e Bacelar, 2001), o que ocorre na estação chuvosa (Moussa e Kahn, 1996), quando os solos estão mais úmidos, e, logo retêm mais o calor. A aplicação de temperaturas adequadas, ou estratificação quente, associados à embebição das sementes, visando acelerar o metabolismo de germinação em sementes de palmeiras, vem sendo sugerido há 50 anos para diversas espécies desta família (Rees 1959; Rees 1962, Odetola, 1987).

A variável índice de velocidade de emergência (IVE) foi maior em sementes embebidas, independente da temperatura e do período, concordando com os resultados encontrados em várias espécies de palmeiras, onde a embebição das sementes por períodos variando de 1 a 14 dias aumentaram a velocidade de germinação (Odetola ,1987; Moussa et al.,1998; Ferreira e Gentil, 2006).

Os fatores temperatura e período de embebição influenciaram de forma isolada a variável "sementes mortas". Quando comparadas as diferentes temperaturas de embebição, verificou-se que a de $30^{\circ} \mathrm{C}$ proporcionou menor quantidade de sementes mortas (35\%), em relaçáo à de $35^{\circ} \mathrm{C}(48 \%)$. As sementes embebidas pelo período de quatro dias apresentaram menor mortalidade $(38 \%)$ apenas em relação às embebidas por dois dias. A alta quantidade de sementes mortas, de um modo geral, ajuda a explicar a baixa germinação em todos os tratamentos. $\mathrm{O}$ maior tempo de avaliação em viveiro pode ter ocasionado o apodrecimento de muitas sementes que podem ter apresentado o intumescimento do "pecíolo cotiledonar" (botão germinativo), não chegando à fase de segunda bainha, critério utilizado no presente trabalho. A deterioraçáo das sementes pode ser causada por agentes fitopatogênicos, que foram verificados (não identificados) ao longo do experimento, além de insetos que penetraram na semente e consumiram o endosperma. $\mathrm{O}$ fato das sementes terem permanecido muito tempo em viveiro, após a semeadura, favorece o aparecimento desses agentes, pois o ambiente oferecia temperatura e umidade adequadas as suas proliferaçóes. $\mathrm{O}$ desenvolvimento de fungos na superfície, que podem penetrar nos embrióes, comprometendo a viabilidade, é um dos principais fatores prejudiciais à germinação de sementes de palmeiras (Loomis, 1958).

O tempo médio de emergência (TME) não foi afetado pela temperatura nem pelo período de embebição, porém 
apresentou efeito de interação significativo entre estes fatores. Sementes embebidas por quatro dias apresentaram redução linear com o aumento da temperatura; a $25^{\circ} \mathrm{C}$ o TME foi de 206 dias, enquanto sob $40^{\circ} \mathrm{C}$ foi de 163 (Figura 2). Temperaturas mais elevadas aceleram o metabolismo e conseqüentemente aumentam a velocidade de germinação (Borges e Rena, 1993). Diante disso, pode-se sugerir uma redução no tempo médio de emergência com o aumento na temperatura, até $40^{\circ} \mathrm{C}$, desde que esta seja mantida por quatro dias, pois a manutençáo da temperatura por seis dias (dados não apresentados), ocasionou um acréscimo de cinco dias no tempo médio (168 dias).

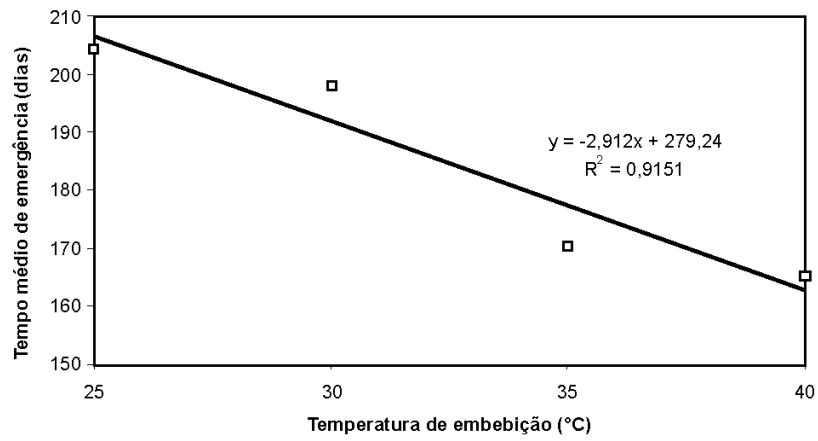

Figura 2 - Tempo médio de emergência de plântulas referentes a sementes de Astrocaryum aculeatum submetidas à embebição por quatro dias sob diferentes temperaturas.

A água influencia na germinação, atuando no tegumento, amolecendo-o, favorecendo a penetração de oxigênio, e permitindo a transferência de nutrientes solúveis para as diversas partes da semente (Toledo e Marcos Filho, 1977). Portanto, tratamentos de pré-semeadura, que envolvem a iniciaçáo metabólica por meio da hidratação de sementes, considerados como de envigoramento, têm sido aplicados com a finalidade de elevar a taxa de germinação, a uniformidade de emergência e a capacidade das sementes resistirem aos efeitos adversos do ambiente (Nath et al., 1991).

A importância do fator água na semente, combinada com alta temperatura constante já havia sido verificada para outras espécies de palmeiras (Koebernik, 1971; Marcus e Banks, 1999). A hidratação ideal é o mais difícil de se obter, pois o excesso de hidratação pode reduzir drasticamente a germinação (Marcus e Banks, 1999), visto que impede a penetração do oxigênio e reduz todo o processo metabólico resultante (Borges e Rena, 1993).

\section{CONCLUSÕES}

A embebição da semente em água favoreceu a emergência de plântulas de Astrocaryum aculeatum, independente da temperatura $\left(25^{\circ} \mathrm{C}, 30^{\circ} \mathrm{C}, 35^{\circ} \mathrm{C}\right.$ e $\left.40^{\circ} \mathrm{C}\right)$ e do período $(2,4 \mathrm{e}$ 6 dias) utilizados. A embebiçáo das sementes na temperatura de $40^{\circ} \mathrm{C}$, por 4 dias, reduziu o tempo médio de emergência da plântula de $A$. aculeatum.

\section{BIBLIOGRAFIA CITADA}

Araújo, M.G. 2005. Morfo-anatomia e desenvolvimento dos frutos e sementes de três espécies da subfamília Arecoideae (Arecaceae). Tese de doutorado. Instituto Nacional de Pesquisas da Amazônia,Universidade Federal do Amazonas, Manaus, 190 pp.

Borges, E.E.L.; Rena, A.B. 1993. Germinação de sementes, p. 83135. In: Aguiar, I.B.; Piña-Rodrigues, F.C.M.; Figliolia, M.B (Coord.). Sementes florestais tropicais. Brasília: Abrates.

Brasil. 1992. Ministério da Agricultura e da Reforma Agrária. Regras para Análises de Sementes. Brasília: CLAV/DNDV/SNDA/MA. 365 pp.

Ferreira, S.A.N. 1996. Maturação fisiológica de sementes de pupunha. Tese de doutorado. Instituto Nacional de Pesquisas da Amazônia,Universidade Federal do Amazonas. 73 pp.

Ferreira, S.A.N.; Gentil, D.F.O. 2006. Extração, embebição e germinação de sementes de tucumã (Astrocaryum aculeatum). Acta Amazonica, 36: 141-146.

Edwards, T.I. 1934. Relations of germinating soy beans to temperature and length of incubation time. Plant Physiology, 9: 1-30.

Gentil, D.F.O.; Ferreira, S.A.N. 2005. Morfologia da plântula em desenvolvimento de Astrocaryum aculeatum Meyer (Arecaceae) Acta Amazonica, 35: 337-342.

Koebernik, J. 1971. Germination of palm seed. Principes, 15: 134137.

Labouriau, L.G. 1983. A germinação das sementes. Washington: OEA. 174 pp.

Loomis, H.F. 1958. The preparation and germination of palm seeds. Principes, 2: 98-102.

Marcus, J.; Banks, K. 1999. A practical guide to germinate palm seeds. Palms, 43: 56-59.

Maguire, J.D. 1962. Speed of germination: aid in selection and evaluation for seedling emergence and vigour. Crop Science, 2: 176-177.

Miranda, I.P.A.; Rabelo, A.; Bueno, C.R.; Barbosa, E.M.; Ribeiro, M.N.S. 2001. Frutos de palmeiras da Amazônia. Manaus: MCT,Instituto Nacional de Pesquisas da Amazônia, 120 pp.

Moussa, F.; Kahn, F. 1996. A importância econômica do tucumãzeiro de Manaus, Astrocaryum aculeatum, p.72. In: Simpósio internacional sobre ecossistemas florestais, 4, Anais, Belo horizonte.

Moussa, H.; Margolis, H.A.; Dubé, P; Odongo, J. 1998. Factors affecting the germination of doum palm (Hyphaene thebaica Mart.) seeds from the semi-arid zone of Niger, West Africa. Forest Ecology and Management, 104: 27-41.

Nath, S.; Coolbear, P.; Hampton, J.G. 1991. Hydratationdehydratation treatments to protect or repair stored 'Karamu' wheat seeds. Crop Science, 31: 822-826.

Odetola, J.A. 1987. Studies on seed dormancy, viability and germination in ornamental palms. Principes, 31: 24-31.

Pessoni, L. A.; Bacelar, C.G. 2001. Efeito da distância da planta-mãe e da estocagem do solo na sobrevivência de tucumã (Astrocaryum 
aculeatum Meyer). In: Reuniāo Especial da SBPC, 7, Anais, Manaus-Am. (CD-ROM).

Pinheiro, C.U.B. 1986. Germinação de sementes de palmeiras: revisão bibliográfica. Teresina: Embrapa-UEPAE. 102 pp.

Rees, A.R. 1959. Germination of oil palm seed: the cooling effect. J. W. Afr. Inst. Oil Palm Res., 3: 76-82.

Rees, A.R. 1962. High-temperature pre-treatment and the germination of seed of the oil palm, Elaeis guineensis (Jacq.). Annals of Botany, 26: 569-581.
Toledo, F.F.; Marcos Filho, J. 1977. Manual das sementes: tecnologia da produção. São Paulo, Agronômica Ceres. 224 pp.

Recebido em 25/02/2009

Aceito em 16/09/2009 